\title{
Depressão e risco de suicídio entre acadêmicos de enfermagem: estratégias de intervenção do docente
}

\author{
Depression and suicide risk among nursing students: teacher intervention strategies \\ Depresión y riesgo de suicidio entre estudiantes de enfermería: estrategias de intervención docente \\ Cynthia Haddad Pessanha Sousa ${ }^{1}$, Claudia Mara de Melo Tavares ${ }^{2}$
}

Como citar esse artigo. Sousa, CHP; Tavares, CMM. Depressão e risco de suicídio entre acadêmicos de enfermagem: estratégias de intervenção do docente. Revista Pró-UniverSUS. 2019 Jul./Dez.; 10 (2): 120-122

\begin{abstract}
Resumo
Introdução: Este estudo pretende abordar a experiência dos discentes e docentes de enfermagem sobre depressão e suicídio nos acadêmicos deste curso. A depressão constitui um sofrimento mental e implica de forma negativa no aprendizado dos alunos, além de aumentar a possibilidade do suicídio entre os jovens com depressão grave. Materiais e métodos: Pesquisa qualitativa com discentes e docentes de enfermagem de uma universidade privada. A sociopoética será usada como método de pesquisa e análise. Em um primeiro momento, o trabalho se dará pelo grupo pesquisador formado por acadêmicos de enfermagem. $\mathrm{O}$ tema gerador será a experiência de algum sentimento relacionado a depressão e suicídio durante a universidade. Em um segundo momento, os alunos irão mencionar docentes que ofereceram suporte emocional neste período. Estes docentes serão entrevistados. Serão realizados três encontros; no terceiro encontro será realizada a contra-análise para que possa ser avaliada, a partir dos dois primeiros encontros, a ocorrência do compartilhamento de estratégias sobre os possíveis caminhos para o enfrentamento de sintomas relacionados a depressão e ideação suicida nestes alunos. Esta contra-análise será o instrumento de validação do estudo. Resultados esperados: Espera-se que ao trazer esta temática os alunos dialoguem sobre suas experiências e os docentes possam refletir sobre possíveis estratégias para continuar a minimizar o sofrimento discente.
\end{abstract}

Palavras-chave: Saúde Mental, Alunos de Enfermagem, Professores Universitários.

\begin{abstract}
Introduction: this study aims to address the experience of nursing students and teachers with depression and suicide in the students of this course. Depression is a mental suffering and negatively implies the learning of students, and increases the possibility of suicide among young people with severe depression. Materials and methods: Qualitative research with nursing students and teachers of a private university. Sociopoetics will be used as a method of research and analysis. At first, the work will be done by the research group formed by nursing students. The generating theme will be the experience of some feeling related to depression and suicide during the university. In a second moment, students will mention teachers who offered emotional support during this period. These teachers will be interviewed. Three meetings will be held; In the third meeting, a counter-analysis will be performed so that, from the first two meetings, the sharing of strategies on the possible ways to cope with symptoms related to depression and suicidal ideation in these students can be evaluated. This counter-analysis will be the validation instrument of the study. Expected Results: It is hoped that by bringing this theme students will dialogue about their experiences and teachers can reflect on possible strategies to continue to minimize student suffering.
\end{abstract}

Keywords: Mental Health, Nursing Students, University Teachers.

\section{Resumen}

Introducción: este estudio busca tratar de la experiencia de estudiantes y maestros de enfermería con la depresión y suicidio en los académicos de este curso. La depresión es un sufrimiento mental y que puede causar perjuicios al aprendizaje de los alumnos, además de elevar la probabilidad de suicidio entre los jóvenes en casos más severos. Materiales e métodos: investigación cualitativa con estudiantes y maestros de enfermería de una universidad privada. La socio-poética será utilizada como método de investigación y análisis. Por primero, el estudio será realizado por el grupo investigador formado por los académicos del curso de enfermería. El tema generador será la percepción acerca de la depresión y el suicidio relacionados a lo largo de la graduación. En seguida, los estudiantes nombrarán maestros que les han ofrecido apoyo emocional en este tiempo. Estos maestros serán entrevistados. Habrá tres citas; En la última, se realizará la contraanálisis para que se pueda evaluar, después de las primeras citas, la ocurrencia de intercambio de estrategias para el enfrentamiento ante los síntomas relacionados a la depresión o al ideario suicida en estos estudiantes. Esta contraanálisis será la herramienta de validación del estudio. Resultados esperados: Se cree en que, trayendo este tema a los estudiantes, los mismos puedan dialogar a cerca de sus experiencias, así como los maestros podrán reflexionar sobre las posibles estrategias para minimizar el sufrimiento de los estudiantes durante la graduación.

Palabras clave: Salud Mental, Académicos de Enfermería, Introdução

Afiliação dos autores: 1. Enfermeira. Mestranda do programa de Mestrado Profissional em Ensino na Saúde/MPES, UFF, RJ, Brasil. Email: cy.haddad@gmail.com ORCID: https:// Afcidiação dos autores: 1. Enferm $00001-5685-4775$

2. Enfermeira. Professora do Programa de Mestrado Profissional em Ensino na Saúde/MPES, UFF, RJ, Brasil. Email: claudiamarauff@gmail.com ORCID: https://orcid.org/00000002-8416-6272 


\section{Introdução}

Ao ingressar na universidade, o estudante passa por inúmeros processos, dentre eles a mudança da rotina de estudo que apresentará mais exigências devido a profundidade dos conteúdos, avaliações, embates entre as tarefas e o lazer, administração do tempo e por vezes conflitos com alguns professores. Além dessas questões, para alguns há o afastamento dos familiares, troca de moradia, expectativas para o futuro entre outras situações que podem impactar em sua saúde mental e talvez resultar em sofrimento psíquico. ${ }^{1}$

É importante destacar que a saúde mental não é restrita a ausência de transtornos mentais e sim abrange um conjunto de fatores, sejam eles sociais, biológicos e psicológicos. Sendo assim, esse conceito assume uma complexidade de aspectos fazendo que com o sujeito possa ser olhado por inteiro, inclusive através de sua história de vida. ${ }^{2}$

O sofrimento psíquico também é traduzido pela junção dos mesmos fatores citados acima, entretanto, há sintomas que contribuem para o adoecimento mental, a sintomatologia e a tolerância a determinadas situações variam de acordo com o contexto em que o indivíduo está inserido e sua vulnerabilidade a determinada questão. $^{3}$

No que tange a vida universitária, sabe-se que a mesma exige do estudante um amadurecimento que muitas vezes pode ser acompanhado de angústias por não corresponder as exigências do meio acadêmico, somado a preocupação e insegurança. Esses sentimentos podem resultar em graves transtornos como a depressão. ${ }^{4}$

A depressão é uma alteração de humor caracterizada por sinais e sintomas neurovegetativos, afetivos, relacionados a volição, autovaloração e cognição. Em alguns casos, podem aparecer sintomas psicóticos como delírios e alucinações além de alterações na psicomotricidade. ${ }^{5}$

É fundamental que os estudantes percebam alguns sintomas relacionados a depressão para que possam lidar com eles e compartilhar com seus colegas ou professores como forma do alívio desses sentimentos.

Essas emoções quando não compartilhadas ou não expressadas, podem resultar em algumas consequências refletindo no âmbito físico e psicológico destes indivíduos. ${ }^{6}$ Dessa forma, como os professores estão mais próximos dos discentes, acredita-se que eles sejam capazes de oferecer um suporte emocional nos momentos em que o aluno precisar.

Não se espera que o saber dos professores acerca da depressão seja profundo, entretanto, é crucial desejar aprimorar e acrescentar um novo saber que venha a ser frutuoso para a eficácia do aprendizado. Na sociedade atual há casos de depressão que infelizmente resultam em alguns suicídios.
Diante de inúmeros desafios os educadores possuem um importante e difícil papel no reconhecimento desses alunos, com o intuito de ofertar um apoio emocional e encaminhar para um profissional capacitado, caso seja necessário.

Sendo assim, o presente estudo apresenta como questões norteadoras: como os alunos de enfermagem lidam com as emoções? Desde o ingresso a universidade foi experimentado algum sentimento relacionado a tristeza, melancolia e desmotivação? Durante o seu percurso acadêmico, qual foi a experiência de suporte emocional ofertado pelos docentes? Como o docente acolhe as demandas do sofrimento destes alunos? Como ele lida com isso?

O objetivo geral é pesquisar sobre a experiência dos discentes e docentes acerca da depressão e suicídio. Os objetivos específicos são: analisar como os estudantes lidam com as emoções e qual impacto as mesmas possuem em seu processo de ensino aprendizagem; descrever as emoções citadas pelos alunos como negativas; compreender o conhecimento dos docentes acerca das reflexões relacionadas ao sofrimento psíquico vivenciado por alguns discentes no decorrer do seu percurso acadêmico; discutir possíveis intervenções frente a este sofrimento diante da singularidade de cada aluno; modelar um curso de capacitação para docentes de enfermagem e criar um instrumento "check-list" como forma de validar este curso.

\section{Materiais e Métodos}

Trata-se de um estudo qualitativo com abordagem sociopoética. ${ }^{7}$ Os participantes serão discentes, do curso de graduação em enfermagem do $6^{\circ}$ e $7^{\circ}$ período que desejarem voluntariamente participar do estudo e docentes de enfermagem que possam ser mencionados pelos alunos como aqueles que ofereceram um suporte emocional ao mesmo. Os critérios de inclusão são alunos que cursam o $6^{\circ}$ e $7^{\circ}$ período (acredita-se que esses alunos apresentaram maiores vivências e contatos com grande parte dos docentes) e professores que foram citados pelos discentes como docentes que proporcionaram um respaldo emocional.

Os critérios de exclusão são alunos menores de idade, alunos de períodos inferiores ao $6^{\circ}$ período e professores que não forem citados pelos discentes.

O cenário da pesquisa será na Universidade Estácio de Sá, campus Sulacap, localizado na zona oeste da cidade do Rio de Janeiro.

A princípio este estudo seria realizado somente com os professores de enfermagem e as questões norteadoras abordariam sobre o conhecimento que os docentes apresentam acerca da depressão e suicídio nos acadêmicos de enfermagem e quais seriam as intervenções realizadas. Entretanto, a pesquisadora 
apresentou dificuldades em reunir os docentes uma vez que alguns estavam em campo prático e o horário dos demais não coincidia com seu horário disponível.

Além dessa questão, houve o acréscimo dos alunos como sujeitos dessa pesquisa pois foi refletido que a presença desses indivíduos no estudo seria enriquecedora visto que suas angústias muitas vezes não são percebidas e perpassam por situações vividas no âmbito universitário.

Os docentes permanecem como sujeitos do estudo pois acredita-se que os mesmos são cruciais na história dos alunos.

A produção de dados será realizada em três momentos: na primeira etapa ocorrerá uma reunião com o grupo-pesquisador realizando uma abordagem artística com base sociopoética partindo do tema gerador.

Neste primeiro encontro ocorrerá a apresentação da pesquisadora e dos participantes de forma descontraída e criativa. Posteriormente, será realizado um relaxamento com o grupo. $\mathrm{O}$ relaxamento proporciona ao co-pesquisador aproximar-se do nível que a psicanálise recomenda, cada indivíduo expressa a imagem ou reflexão que possa vir a surgir, sem censura ou receio. Em uma perspectiva "oriental", as energias fluem de modo mais livre quando há momentos de relaxamento. ${ }^{8}$

Em um segundo momento, será realizada uma entrevista semi-estruturada com os professores que forem citados pelo grupo-pesquisador como referências positivas de suporte emocional. A entrevista buscará relatar alguma situação descrita pelo docente que apresentou impacto direto nas emoções do discente e consequentemente interferiu em seu processo de ensinoaprendizagem.

No terceiro momento, será realizada a contraanálise pelo grupo-pesquisador baseado em seus achados tanto através de suas falas quanto por meio de expressões sociopoéticas.

Este estudo foi submetido ao Comitê de Ética em Pesquisa da Faculdade de Medicina da Universidade Federal Fluminense (UFF), cumprindo o que preconiza a Resolução no 466/12 (CNS), e aguarda a aprovação.

\section{Resultados esperados}

Espera-se que os alunos possam dialogar sobre suas emoções de forma a perceber como lidar com sentimentos negativos e qual modo é mais propício para verbalizar essas emoções. Além disso, é fundamental que os docentes possam refletir em estratégias que permitam minimizar o sofrimento discente e construir uma relação de empatia e confiança.

A dificuldade em lidar com alguns alunos somado a administração de questões pessoais e a grande demanda dos discentes pode ser um empecilho para a construção de vínculos, contudo sabe-se que ao impactar de modo positivo a vida do acadêmico, o professor pode diminuir um sofrimento psíquico e, consequentemente contribuir para o alívio da dor deste aluno.

\section{Referências}

1. Nogueira-Martins LA, Nogueira-Martins MCF. Saúde Mental e Qualidade de Vida de estudantes universitários. Revista Psicologia, Diversidade e Saúde. 2018, 7(3), 334-337. doi: 10.17267/2317-3394rpds. v7i3.2086.

2. Moreira JCR, Pinho JRO. A saúde mental nos dias de hoje. Retraction of: Silva MSD, (Org). São Luís, 2013.

3. American Psychiatric Association. Manual diagnóstico e estatístico de transtornos mentais [recurso eletrônico]: DSM-5. Porto Alegre: Artmed, 2014. Tradução: Maria Inês Corrêa Nascimento...; revisão técnica: Aristides Volpato Cordioli... - 5. Ed. - Dados eletrônicos.

4. Da Victória MS et al. Níveis de ansiedade e depressão em graduandos da Universidade do Estado do Rio de Janeiro. Revista de Psicologia. 2013;16(25):163-175.

5. Delgallarondo P. Psicopatologia e semiologia dos transtornos mentais 2 ed. Porto Alegre: Artmed, 2008

6. Campos Nunes P, Mendonça Saraiva A, Gonçalves de Moura S, De Castro Silva PM, De Oliveira Ferreira Filha Correio M, Teotônio Bezerra Correio, ST. "Coração de estudante": a terapia comunitária integrativa no contexto universitário. Revista de Pesquisa Cuidado é Fundamental Online, 2015; 7(3):2919-2929.

7. Tavares CMM. Como desenvolver experimentações estéticas para produção de dados na pesquisa sociopoética e abordagens afins? Revista Pró-UniverSUS. 2016 Jul./Dez.; 07 (3): 26-31.

8. Fonseca PIMN, Silveira PG, Tavares CMM, Carvalho JC. A plasticidade criativa possibilitada pela sociopoética: a perspectiva da criação de relaxamentos. Revista Portuguesa de Enfermagem de Saúde Mental. 2017.Spe. 5: 99-106 